\title{
Alkoxylation for Surfactant Productions: Toward the Continuous Reactors
}

\author{
Riccardo Tesser ${ }^{1}$, Vincenzo Russo ${ }^{1,2}$, Elio Santacesaria ${ }^{3}$, Wiesław Hreczuch ${ }^{4}$ and \\ Martino Di Serio ${ }^{1 *}$ \\ ${ }^{1}$ Department of Chemical Sciences, University of Naples Federico II, Naples, Italy, ${ }^{2}$ Laboratory of Industrial Chemistry and \\ Reaction Engineering, Åbo Akademi University, Turku, Finland, ${ }^{3}$ Eurochem Engineering, Milan, Italy, ${ }^{4}$ MEXEO, \\ Kedzierzyn-Kozle, Poland
}

Alkoxylation is surely an important reaction as it is industrially used to produce surfactants. The actual technology is to convert ethylene oxide/propylene oxide with a long-chained alcohol, catalyzed by a homogeneous catalyst (e.g., KOH). Traditionally, the operation is conducted in semi-batch systems characterized by a low productivity. As the demand of surfactant production is increasing, it is natural to shift to a continuous process. In the present review article, the most recent efforts dealing with the alkoxylation processes in continuous are reported, analyzing critically the results reported in both the scientific and patent literature.

OPEN ACCESS

Edited by:

Ernesto Salzano,

University of Bologna, Italy

Reviewed by:

Mohsen Sarafraz,

University of Adelaide, Australia Narendra Kumar,

Åbo Akademi University, Finland

*Correspondence: Martino Di Serio diserio@unina.it

Specialty section

This article was submitted to Chemical Reaction Engineering

a section of the journal

Frontiers in Chemical Engineering

Received: 30 April 2020

Accepted: 07 July 2020

Published: 21 August 2020

Citation:

Tesser R, Russo V, Santacesaria E Hreczuch W and Di Serio M (2020)

Alkoxylation for Surfactant

Productions: Toward the Continuous Reactors. Front. Chem. Eng. 2:7. doi: 10.3389/fceng.2020.00007
Keywords: alkoxylation, scale-up, continuous reactor, microreactor, surfactant production

\section{INTRODUCTION}

The alkoxylation reactions are generally performed in semi-batch gas-liquid reactors (Di Serio et al., 2005; Santacesaria et al., 2018), also in series, in which the catalyst and the substrate (alkyl phenols, fatty alcohols, organic acids, or amines) are initially charged (Di Serio et al., 2015). On the other hand, the epoxide (ethylene or propylene oxide) is added in fed-batch modality during the first step of the reaction course. Finally, the reaction is completed in a "digestion" step in which the residual epoxide, in gas and in the liquid phase, is completely reacted. This process strategy is a result of the high reactivity of alkoxides and to the high heat involved in alkoxylation reactions (around $90 \mathrm{~kJ} / \mathrm{mol}$ ). The use of semi-batch reactors, however, has some drawbacks that can be summarized in the following points: (1) the reactor volume is relatively high, and this aspect could represent a serious problem for safety issues (Gustin, 2000; Di Serio et al., 2005; Salzano et al., $2007 \mathrm{a}, \mathrm{b})$ owing to the high quantity of alkoxide present in the gas phase of the reactor at a certain time; (2) the productivity of the system is quite low for the various steps involved in a semi-batch process (reactant and catalyst charge, chemical reaction, products discharge); (3) the safety of the overall process is not optimal, a fact owing to possible epoxide accumulations that could easily lead to runaway reactions (Gustin, 2000; Di Serio et al., 2005; Salzano et al., 2007a,b).

A possible reactor configuration that could allow overcoming the mentioned drawbacks is the adoption of a continuous reactor that can be properly designed for the achievement of the desired alkoxylation degree and high productivity. The shift from the traditional semi-batch process to the continuous ones could really represent the start of a new era in the alkoxylation technologies (Santacesaria et al., 2018). Moreover, a continuous process must be designed to operate under high pressure, and this could represent a further advantage for the safety owing to the absence of a vapor phase (Di Serio et al., 2005) rich in alkoxide that could be more susceptible to ignition. The 
TABLE 1 | Summary of the typical reaction conditions and related results for different alkoxylation processes performed in continuous reactors.

\begin{tabular}{|c|c|c|c|c|c|c|c|c|}
\hline Reactor & Alcohol (alkoxide) & $\boldsymbol{C}_{\text {cat }}$, wt. $\%$ & Type of catalyst & Alcohol/alkoxide & $\boldsymbol{T}_{\text {max }},{ }^{\circ} \mathbf{C}$ & $\tau, \mathbf{s}$ & $P, \mathrm{~kg} /\left(\mathrm{h} \mathrm{m}^{3}\right)$ & References \\
\hline Coiled tubes & $\mathrm{C}_{12-14}(\mathrm{EO} / \mathrm{PO})$ & 0.10 & $\mathrm{NaOCH}_{3}$ & $1: 1-1: 6 \mathrm{~mol} / \mathrm{mol}$ & 287 & 25 & 120,000 & Umbach and Stein, 1971 \\
\hline Coiled tubes & Sucrose (EO/PO) & 0.40 & $\mathrm{KOH}$ & $11.4: 5.8 \mathrm{w} / \mathrm{w}$ & 180 & 600 & - & Hinz and Dexheimer, 2002 \\
\hline Microchannels & Butanol (EO/PO) & $3.00^{*}$ & $\mathrm{KOCH}_{3}$ & $1: 35 \mathrm{~mol} / \mathrm{mol}$ & 190 & 200 & - & Hubel et al., 2010 \\
\hline Microchannels & Octanol (EO) & $0.66^{\star}$ & $\mathrm{KOH}$ & $1: 3-1: 6-1: 9 \mathrm{~mol} / \mathrm{mol}$ & 240 & 50 & 12,600 & Rupp et al., 2013a,b \\
\hline Falling film multipipe & n-Nonyl phenol (EO) & 0.60 & $\mathrm{NaOH}$ & $1: 7 \mathrm{~mol} / \mathrm{mol}$ & 220 & 160 & 22,000 & Aigner et al., 2016 \\
\hline Microreactor & Butanol (EO) & 5.00 & $\mathrm{KOH}$ & $1: 9 \mathrm{~mol} / \mathrm{mol}$ & 150 & 300 & - & Dessimoz, 2011 \\
\hline Stirred compartments & Polyoxypropylentriol (PO) & 0.05 & DMC & $1: 4.2 \mathrm{w} / \mathrm{w}$ & 120 & 15,000 & 324 & Yamada et al., 2006 \\
\hline CSTR & $\mathrm{C}_{13}(\mathrm{EO})$ & 0.18 & $\mathrm{La}\left(\mathrm{PO}_{4}\right)$ & $1: 1.4 \mathrm{w} / \mathrm{w}$ & 170 & 7,200 & 450 & McDaniel and Reese, $2007 a$ \\
\hline Two CSTR & $\mathrm{C}_{12-16}(\mathrm{EO})$ & 0.0144 & $\mathrm{DMC}$ & $1: 1.4 \mathrm{w} / \mathrm{w}$ & 130 & 12,960 & 255 & McDaniel and Reese, 2007b \\
\hline Two CSTR & Nonylphenol ethoxylate (EO) & 0.0133 & $\mathrm{DMC}$ & $1: 1.9 \mathrm{w} / \mathrm{w}$ & 130 & 13,320 & 195 & McDaniel and Reese, 2008b \\
\hline CSTR + PFR & $\mathrm{C}_{26}$ diol (EO/PO) & 0.3 & $\mathrm{DMC}$ & $1: 9$ w/w & 140 & 21,600 & 150 & Villa et al., 2014 \\
\hline $\mathrm{CSTR}+\mathrm{PFR}$ & Glycerol alkoxylate (PO) & 0.0058 & DMC & $1: 4.2 \mathrm{w} / \mathrm{w}$ & 125 & 8,700 & 372 & Verwijs et al., 2008 \\
\hline CSTR + PFR & Glycerol (EO/PO) & 0.4 & $\mathrm{DMC}$ & $1: 10.3 \mathrm{w} / \mathrm{w}$ & 160 & 25,200 & 130 & Weston et al., 2012 \\
\hline Two CSTR & Glycerol (EO/PO) & 0.002 & DMC & $1: 2.7: 33.1$ w/w (EO/PO) & 140 & - & 653 & Lai et al., 2019 \\
\hline
\end{tabular}

$\tau$, residence time; $P$, productivity. ${ }^{*}$ mol\%.

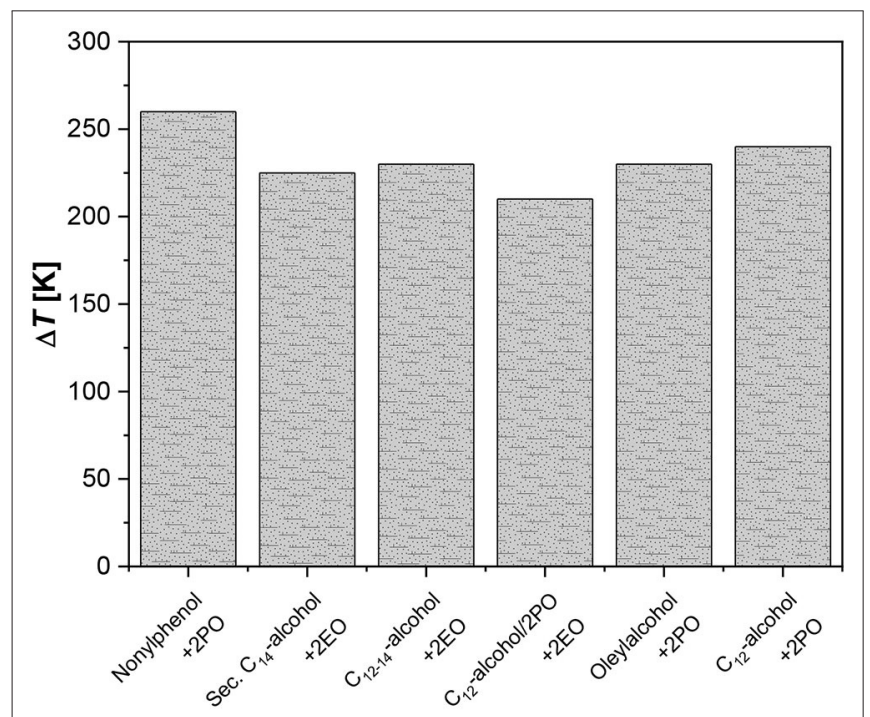

FIGURE 1 | Temperature peaks for the ethoxylation of fatty alcohols. Data from Rupp et al. (2013a,b).

adoption of a sufficiently high pressure can ultimately keep the alkoxide in liquid state at the process temperature realizing high concentration with an improvement of the reaction rate.

In the scientific and patent literature, both traditional reactors, like the tubular ones, and more innovative reactor configurations, like microreactors, have been proposed for the continuous alkoxylation reactions. These last are particularly suitable for exothermic and multiphase reactions, thanks to the high heat and mass transfer exchange rate (Kralisch et al., 2012; Russo et al., 2013). Moreover, very recently, also stirred tank reactors in series or in combination with PFRs have been proposed as suitable for a continuous alkoxylation production process. In fact, whereas innovative microreactors showed superior performances in terms of heat/mass transfer efficiency and in theoretical productivity, many authors still proposed the use of traditional reactor devices accepting the drawbacks (lower productivity, lower heat transfer efficiency) but gaining in the possibility for large-scale applications. On the other hand, the exploitation of microdevice advantages can be achieved through the concept of numberingup (instead of scale-up) that involves, however, a complex setting and control. Hybrid emerging technologies, for example, annular thin film reactor (tube-in-tube arrangement) of corrugated plate heat exchanger reactor, could represent a good perspective in the industrial consolidation of continuous alkoxylation.

In the present paper, the state-of-the-art of such proposals is examined, compared, and extensively discussed, also considered for a possible industrial perspective in terms of productivity of different systems.

\section{DISCUSSION}

From a literature survey of the last decades, several attempts in performing the alkoxylation process in continuous devices have been made. In Table 1, examples of the reaction conditions adopted by different authors are summarized and compared, also in terms of system productivity expressed as the quantity of product obtained per unit of time and per unit of reactor volume.

By using tubular reactors, even working under optimized process conditions of pressure and temperature, there are problems in the thermal control of the system. This fact has been solved by diluting the ethylene oxide concentration by splitting the feed at different points along the tubular reactor. This solution leads to drawbacks and difficulties owing to the necessity of a very complex process control system, particularly in the case of high numbering-up (replication of multiple reactor modules) (Umbach and Stein, 1971; Hinz and Dexheimer, 2002; Hubel et al., 2010; Nikbin et al., 2018).

A possible solution to the control of temperature can be the use of a coiled tubular reactor as suggested in a 
pioneering work of Umbach and Stein (Rupp et al., 2013a,b). In their investigation, these authors have tested ethoxylation and propoxylation reactions in two types of tubular reactors consisting in a stainless-steel tube of different diameters (6 and $9 \mathrm{~mm}$ ) arranged as coils. With this experimental setup, the authors were able to obtain a complete conversion of alkoxides in very short residence times, in the range $15-150 \mathrm{~s}$, which is much lower than the resident time characteristic of discontinuous processes. The system is operated under high pressure (60-100 bar) to maintain ethylene or propylene oxide in liquid state while the temperature of the feed is quite low $\left(60-70^{\circ} \mathrm{C}\right)$.

The two reactors are designed with a very high $L / D$ ratio (respectively, 2,500 and 1,400) for a better performance in heat removal; nevertheless, rather high temperatures were reached along the reactor with a characteristic profile. The achieved temperature peaks obtained with different systems tested by the authors can be observed in Figure 1.

As it can be seen, the maximum temperatures reached were in the range of $240-300^{\circ} \mathrm{C}$. Even if only reactions with low alkoxylation degrees were tested in this investigation (2-4 mol alkoxide/mol substrate), the productivities obtained resulted very interesting, giving place to a product throughput up to $100-$ $120 \mathrm{~kg} / \mathrm{h}$ that corresponds to a monthly production of $60-70$ tons and with a specific productivity of $120,000 \mathrm{~kg} /\left(\mathrm{h} \mathrm{m}^{3}\right)$. The same concept has been developed for sucrose-based polyether production, in the patent by Hinz and Dexheimer (2002). These authors used concentrated aqueous solution of sucrose $(60 \%$ by weight) as substrate to be epoxidized and various mixtures of EO and $\mathrm{PO}$ as epoxide mixture. The employed catalyst was $\mathrm{KOH}$ at 0.4 wt.\%. For example, by using two reactor modules connected in series, with a thermostatting fluid, respectively at 140 and $180^{\circ} \mathrm{C}$ and with a feed ratio of sucrose solution and epoxides equal to $11.4: 5.8$, they obtain an average ratio of (EO, PO)/sucrose of around $5.2 \mathrm{~mol} / \mathrm{mol}$. The adopted reaction pressure was 36.5 bar.

The concept of using a reactor of high $L / D$ ratio, for maximizing the heat removal efficiency, can be further stressed by passing to microreactors. Hubel et al. (2010) used different microchannel devices patented in 2010 to perform the alkoxylation of alcohols. The authors stated that microdevices are characterized by a very high efficiency in both mass and heat transfer. In this way, it is possible to run the reaction in safe conditions by using microplates, whose microchannels (capillaries of a $600 \mu \mathrm{m}$ hydraulic diameter) are optionally coated with catalysts, where alcohol and epoxide are mixed directly at the entrance of the plate (see Figure 2). In this way, the two solutions get totally mixed and temperature peaks are avoided. The described setups allow working in different configurations, characterized by the presence of heating/cooling plates that are alternated to plates where catalyst is present. The configurations differ in how the epoxide is fed to the reactor. In fact, it is possible to either feed the entire stream to the first plate or feed the mentioned stream in different points of the microreactor, keeping its concentration almost constant along the axial coordinate. The authors claim that a system like that can work at a temperature up to $400^{\circ} \mathrm{C}$ and at a pressure up to 800 bar, to keep the reaction media in liquid phase. From the different examples that the author reported, it is interesting to observe that by working with a residence time of $200 \mathrm{~s}$ at $190^{\circ} \mathrm{C}$ and 120 bar, it is possible to achieve $99.6 \%$ conversion.

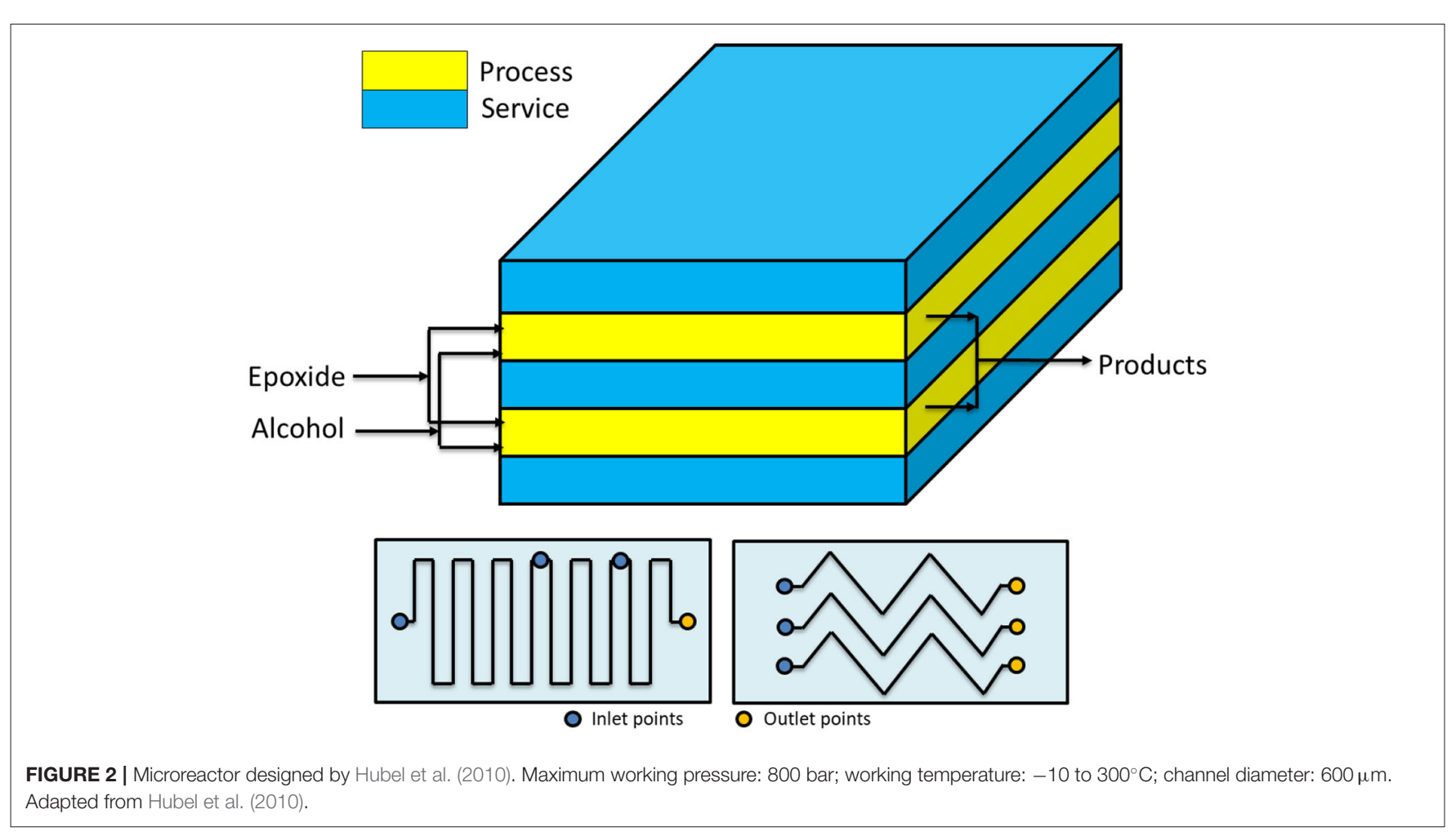




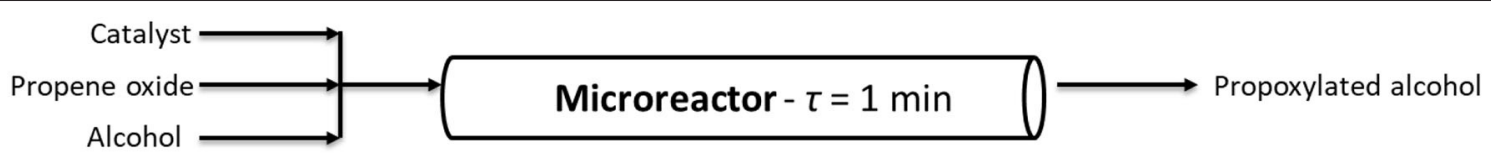

FIGURE 3 | Microinnova alkoxylation plant scheme.

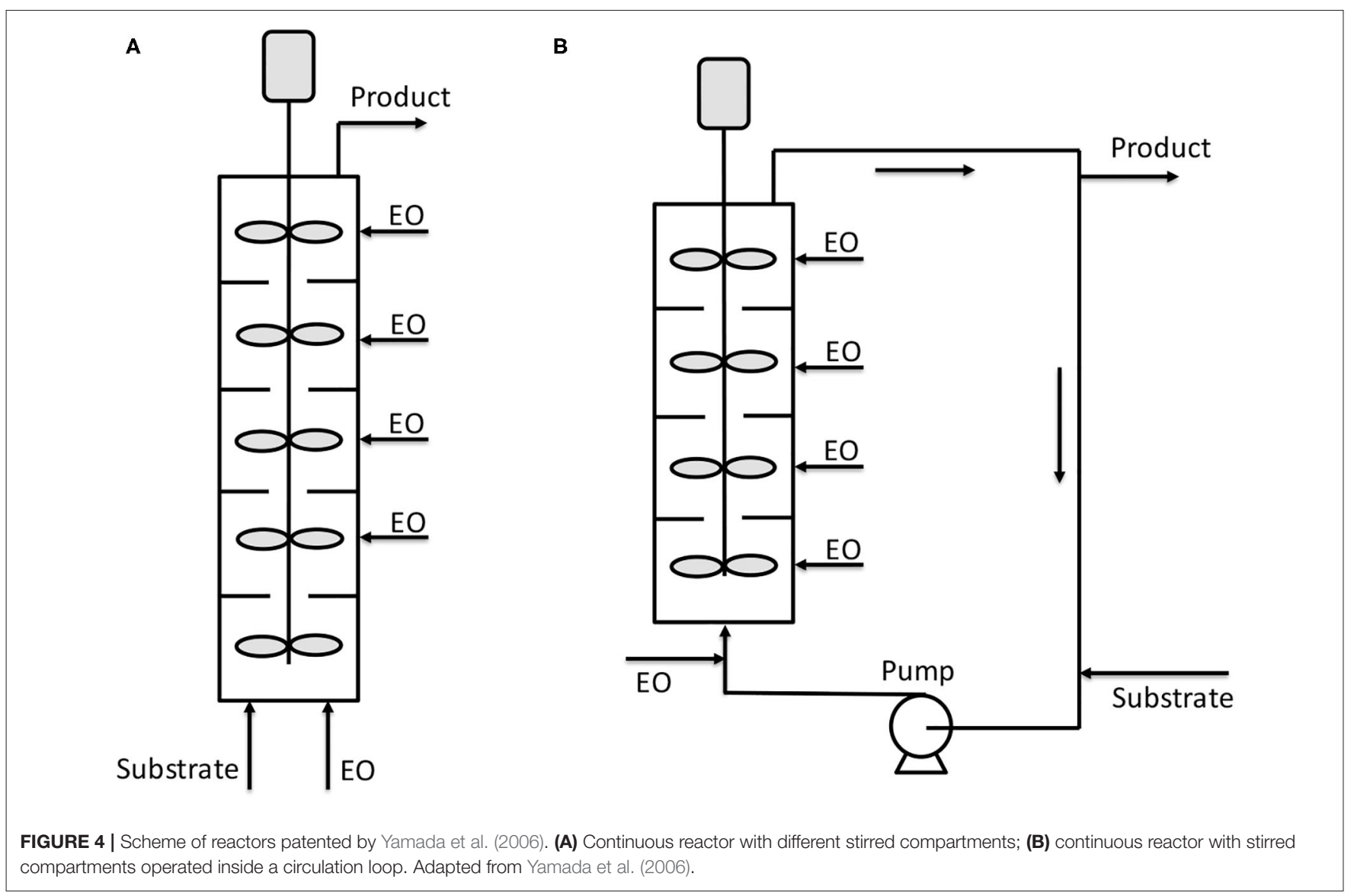

Different EO/butanol molar ratios were used between 9 and 65. The microreactors shown in Figure 2 have two possible channel structures for the reaction side that differ in geometry (one is zig-zagged, the other step-wised) and the possibility to feed fresh reactants also along different positions of the channel itself.

Moreover, the authors claim that a relatively high ethoxylation degree can be achieved in the microstructured device described previously. A molar ratio $\mathrm{EO} /$ alcohol of 35 with a polydispersity index of 1.06 was achieved by using the conditions reported in Table 1 and potassium methoxide $(3 \mathrm{~mol} \%)$ as catalyst. In this way, a very low concentration of unreacted EO $(<10 \mathrm{ppm})$ was found in the reactor outlet stream.

In 2011, Anne-Laure Dessimoz reported data of a laboratoryscale microreactors for ethoxylation reactions, performing kinetic investigations at $250^{\circ} \mathrm{C}$ and 50 bar (Dessimoz, 2011), claiming a productivity higher than the conventional semibatch reactors. An increase of a factor 2.5 was observed for productivity of a high-pressure two-phase reactor while

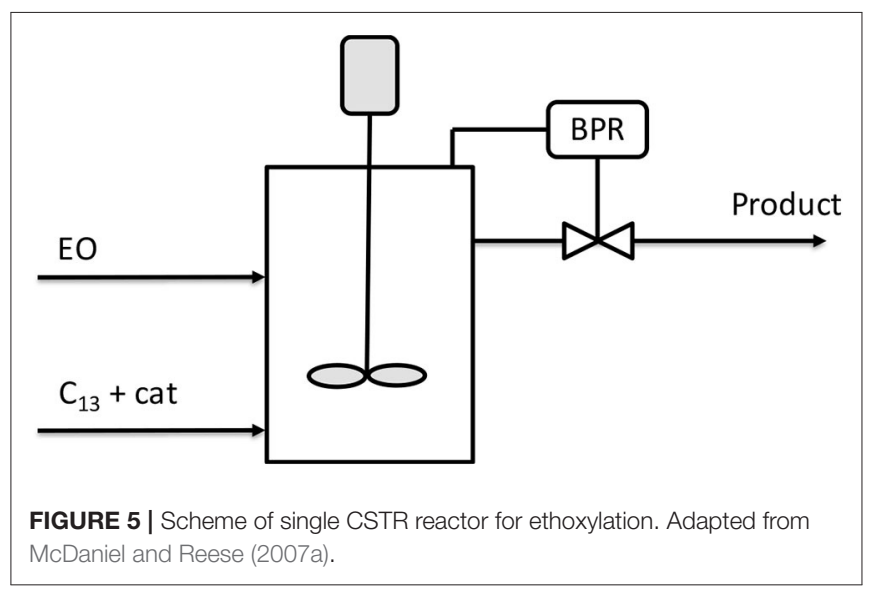

a factor of 6 was obtained in a multi-injection reactor in which ethylene oxide feed was split in multiple points along the reactor. 


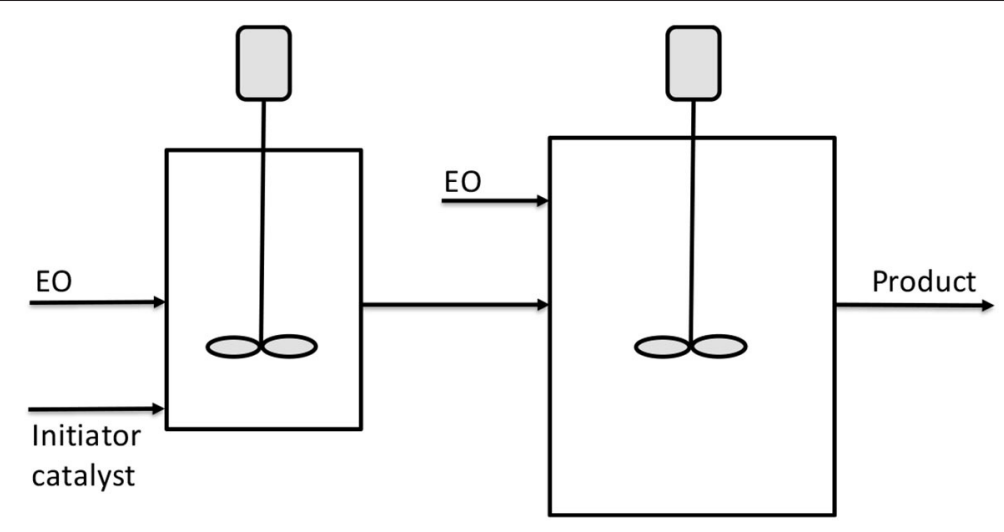

FIGURE 6 | Scheme of CSTR reactors in series for ethoxylation. Adapted from McDaniel and Reese (2007b).
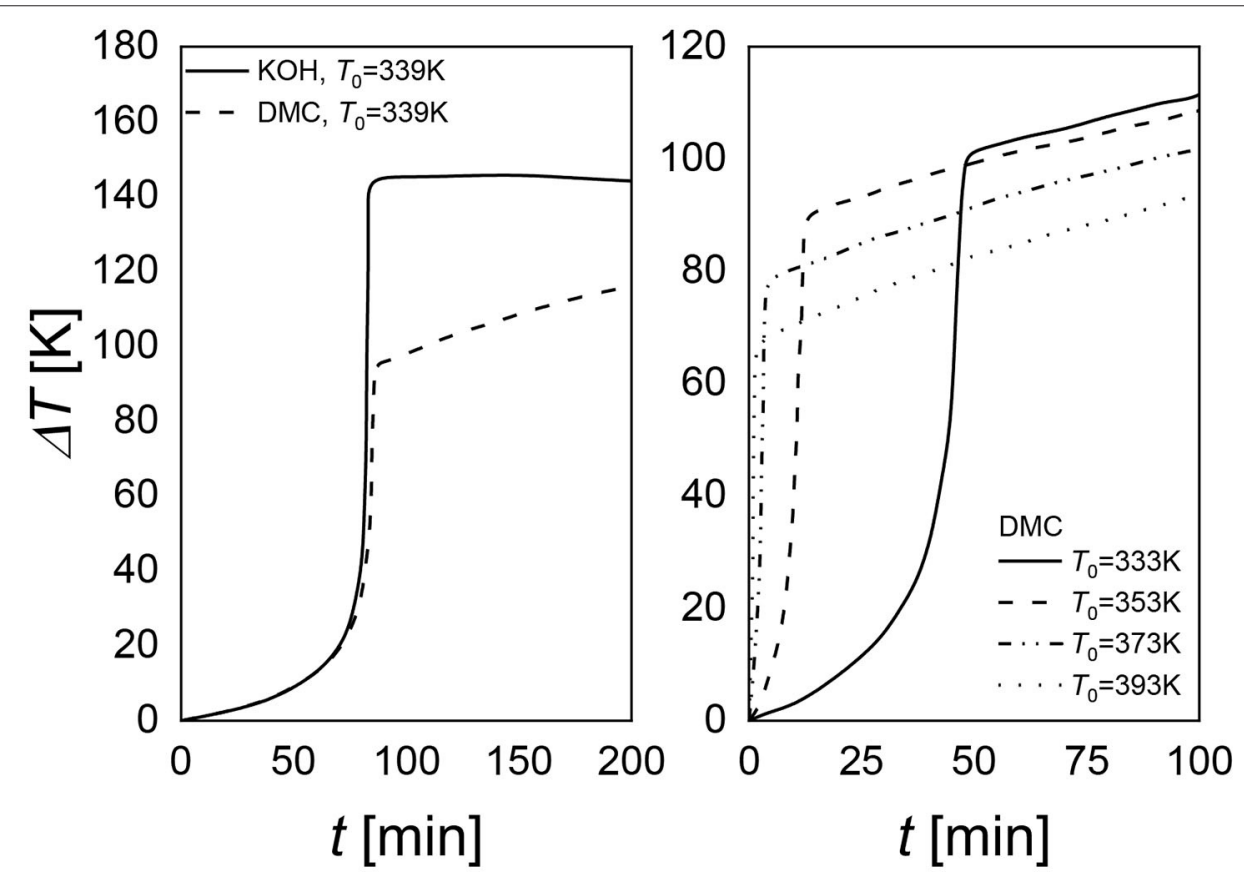

FIGURE 7 | Comparison of the maximum achievable temperature for $\mathrm{KOH}$ and DMC catalyst (right). DMC performances at different initial temperature values (left).

The same strategy was adopted by Rupp et al. (2013a,b) who studied octanol ethoxylation by using a single microchannel reactor immersed in a thermostatic bath. These authors performed an extensive experimental and modeling investigation on the possibility to continuously produce ethoxylated octanol, to a various degree, in a short residence time with interesting productivity results. The reactors used in this study are characterized by $L / D$ ratio in the range 2,000-4,600 and are constituted by microchannels with diameters of respectively, 250 and $876 \mu \mathrm{m}$. The feed to the reactor consists in two separate streams: one contains octanol and dissolved catalysts (potassium octanoate) and the other is ethylene oxide in the desired ratio. Just before the reactor, a micromixer (SIMM V2 by IMM, Mainz) is installed to ensure a complete mixing and homogenization of the reactants. As before, the pressure was kept in the range 90-100 bar by means of a back-pressure regulator to ensure a liquid-phase reaction and the kinetic investigation of these authors covered the temperature range $130-240^{\circ} \mathrm{C}$. In these operative conditions, a residence time of $50 \mathrm{~s}$ resulted enough to reach a complete conversion of ethylene oxide and to obtain an ethoxylation degree on octanol in the range 3-9. In this specific experimental device, the maximum throughput was $0.5 \mathrm{~cm}^{3} / \mathrm{min}$ that is very low; however, the productivity, defined as the amount of product obtained per hour 


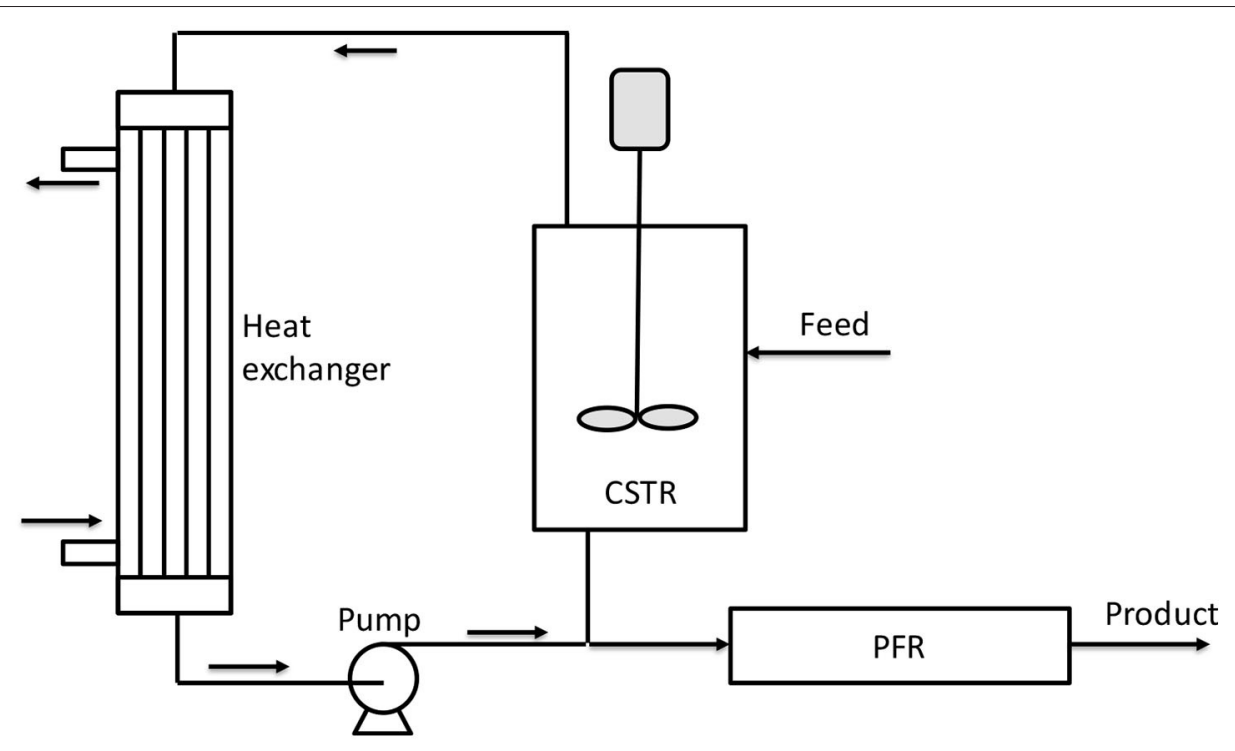

FIGURE 8 | Scheme of reactor combination proposed by Villa et al. (2014). Adapted from Villa et al. (2014).

and per cubic meter of reactor, is on the contrary very high: $12,600 \mathrm{~kg} /\left(\mathrm{h} \cdot \mathrm{m}^{3}\right)$.

The problem of the low productivity of microreactors in the alkoxylation reaction has been recently faced and solved by the Microinnova Engineering $\mathrm{GmbH}$, using a microstructured chemical reactor developed by the Institut für Mikrotechnik Mainz (IMM) GmbH with innovative fabrication techniques reported in Krtschil et al. (2013). The reactor is built with the concept of modularity which allows the manufacture of different reactors according to the requirements of the process (see sketch in Figure 3). Microinnova has designed and built an alkoxylation plant with a productivity of $20 \mathrm{~kg} / \mathrm{h}$. This plant is now on stream and a new plant with a productivity of $200 \mathrm{~kg} / \mathrm{h}$ is in assembly. The authors claim that working with their multiple plate microreactor, it is possible to scale down the reaction times from $12 \mathrm{~h}$ to $1 \mathrm{~min}$, keeping the same product characteristics, with an intensification factor of about 700 .

Other kinds of reactors are also present in the literature which structure is more traditional with respect to the already presented microchannel or microstructured reactors. For example, Yamada et al. (2006) patented a tubular reactor constituted by different plates stirred by dynamic impellers. Both the epoxide and initiator/catalyst mixture are fed from the bottom and the vessel is kept under pressure by an external vessel pressurized with nitrogen. The reactor can be operated also by feeding ethylene oxide in the different stirred sections of the reactor body (see Figure 4A). A second configuration is also shown, where the mentioned reactor is placed in a loop (see Figure 4B). This last setup could be particularly interesting as a heat exchanger can be installed on the circulation line improving the reaction heat removal. In the patent of Yamada et al. (2006), different examples are reported and among them is worth to note a case in which a reactor configuration like the scheme of Figure $4 \mathrm{~A}$ was used. The reactor $(6.5 \mathrm{~cm}$ of internal diameter) was constituted by 10 compartments each of them of $100 \mathrm{~cm}^{3}$ and operated at $120^{\circ} \mathrm{C}$ and 15 bar. The authors worked with the double metal cyanide catalyst (DMC), zinc hexacyanocobaltate complex, first patented by General Tires in 1960's and widely used in alkoxylation reactions (McDaniel and Reese, 2007a). The stirring speed was $900 \mathrm{rpm}$, DMC was used as catalyst with a concentration of 0.05 wt.\% in the initiator. The feed was 2 $\mathrm{g} / \mathrm{min}$ of polyoxypropylentriol as initiator and PO was adopted as epoxide. This last was fed at a rate of $1.68 \mathrm{~g} / \mathrm{min}$ to each 1,3 , 5,7 , and $9^{\circ}$ compartments. After $30 \mathrm{~min}$ of operation, the reactor reached stationary conditions with a complete conversion of $\mathrm{PO}$ and with a polydispersity index of 1.12 and with a productivity of $624 \mathrm{~kg} /\left(\mathrm{h} \mathrm{m}^{3}\right)$.

The strategy to employ CSTR reactor for continuous ethoxylation, instead of tubular reactor, has been extensively studied by (McDaniel and Reese, 2007a,b, 2008a,b). Two interesting examples are reported here to illustrate the approach based on the CSTR reactor. In the first example, a single CSTR reactor of around $1,900 \mathrm{~cm}^{3}$ of volume and equipped with thermal and pressure controls was used to conduct an ethoxylation at $170^{\circ} \mathrm{C}$ at 3 bar with $\mathrm{La}\left(\mathrm{PO}_{4}\right)$ as catalyst $(\mathrm{McD}$ aniel and Reese, 2007a). The scheme of this reactor is reported in Figure 5.

The reactor, initially charged with an ethoxylated $\mathrm{C}_{13} / \mathrm{EO}$ $=6.5$, was fed with $8.34 \mathrm{~g} / \mathrm{min}$ of $\mathrm{EO}$ and $5.83 \mathrm{~g} / \mathrm{min}$ of a mixture $\mathrm{C}_{13} /$ catalyst. With a residence time of $2 \mathrm{~h}$, a complete conversion of EO was reached and the product was characterized with a polydispersity index of 1.12 . In a second example, the same authors adopted the strategy of multiple-stage reactors in series with intermediate feed of EO. The scheme is illustrated in Figure 6.

The two reactors schematized in Figure 7 have a volume of respectively, 4.5 and $9 \mathrm{~L}$. DMC was used as catalyst with a concentration of $144 \mathrm{ppm}$. The first reactor was fed with 23.95 

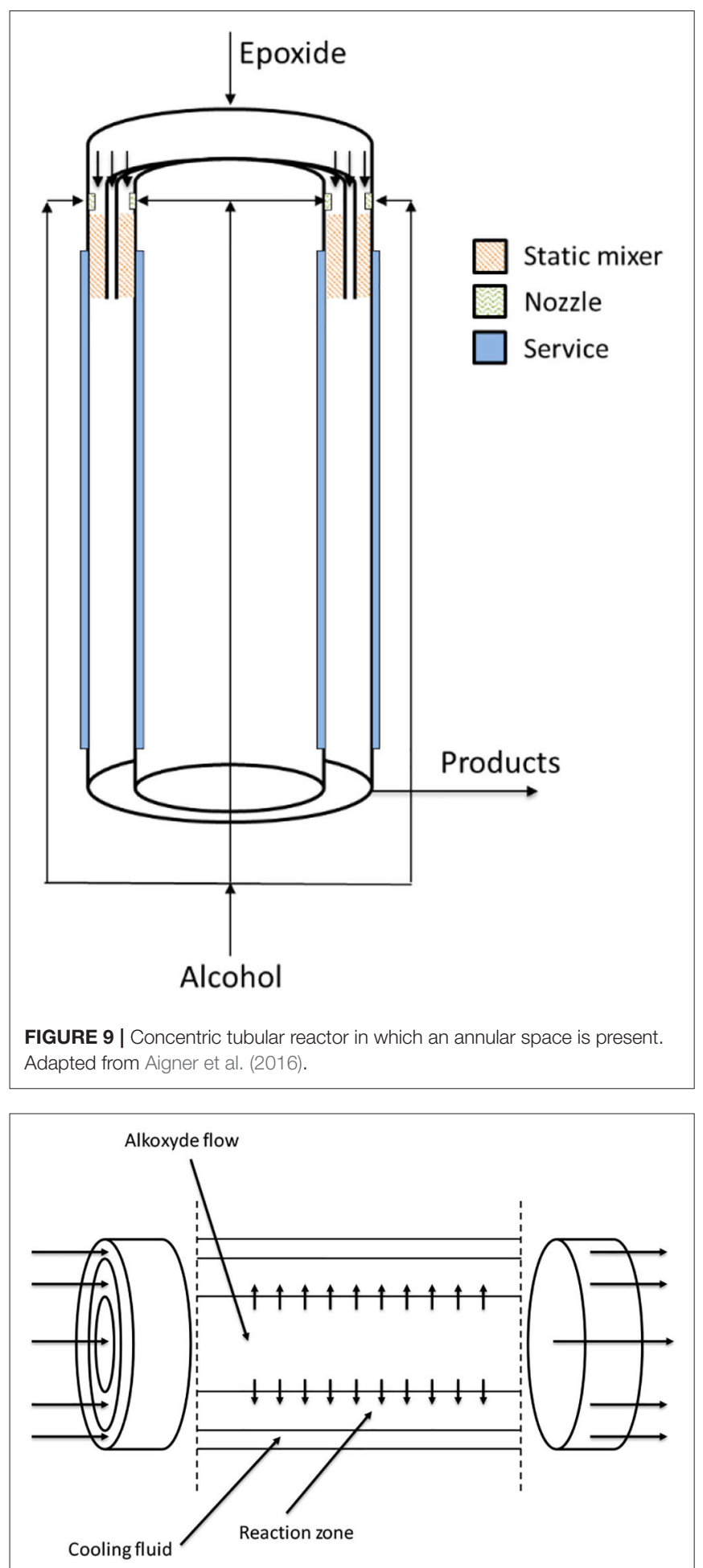

FIGURE 10 | Tubular tube-in-tube reactor proposed by Nikbin et al. (2018). Adapted from Nikbin et al. (2018).

$\mathrm{g} / \mathrm{min}$ of initiator (ethoxylate of Neodol 25) and catalyst in a first stream and with $16.7 \mathrm{~g} / \mathrm{min}$ of $\mathrm{EO}$ in a second stream. A further feed of $16.7 \mathrm{~g} / \mathrm{min}$ of $\mathrm{EO}$ was fed to the second bigger reactor. An overall molar ethoxylation degree of 6.6 was obtained with a residence time of $1.5 \mathrm{~h}$ in the first reactor and $2.1 \mathrm{~h}$ in the second. Finally, a polydispersity index of 1.10 was obtained for the product stream. The same apparatus described in Figure 6 was used by McDaniel and Reese (2008a,b) for the continuous ethoxylation of a different initiator, based on nonylphenol ethoxylate and with DMC catalyst. At $130^{\circ} \mathrm{C}$ and $3.5 \mathrm{bar}$, a productivity of $195 \mathrm{~kg} /\left(\mathrm{h} \mathrm{m}^{3}\right)$ was obtained.

Verwijs et al. (2008), Weston et al. (2012), Villa et al. (2014) showed another interesting aspect of DMC catalyst that could favor their industrial application. These catalysts are thermally deactivated, a fact that increases the safety of the process. By working with this catalyst, it is possible to reduce the maximum temperature that the system can reach. In Figure 7, it is possible to observe that $\mathrm{KOH}$ leads to a higher temperature than DMC. Moreover, starting from different initial temperatures, it is possible to reach different maximum temperatures (Figure 8, left plot). As it is evident, a slope of temperature increase is still present but very smooth. Thus, it is possible to take all the safety procedures to stop the reaction (Dessimoz, 2011).

All these considerations can be better understood if we consider that in Figure 8, the $\Delta T$ is reported as a multiplication factor with respect to the initial temperature (a value of 2 means that the temperature was doubled with respect to the initial). These authors reported a different example in their patent as a reaction in liquid phase under pressure adopting a CSTR reactor enclosed in a circulation loop and a tubular reactor used as digestor of the unreacted monomer (PO). By using glycerol alkoxylate as initiator and propylene oxide as monomer, an overall productivity of $372 \mathrm{~kg} /\left(\mathrm{h} \mathrm{m}^{3}\right)$ was obtained at relatively low temperature $\left(110^{\circ} \mathrm{C}\right.$ in CSTR and $125^{\circ} \mathrm{C}$ in PFR).

For what concerns reactor configuration, in the patent of Villa et al. (2014), different loop continuous systems are proposed and, among them, one is particularly promising and is represented schematically in Figure 8. In an example reported by these authors, two reactors (CSTR and PFR) with a volume of 28 and $25 \mathrm{~L}$, respectively, were used to process a diol of $400 \mathrm{Da}$ and obtain a product of $4,000 \mathrm{Da}$ that corresponds to an EO/S molar ratio of about 80 . The catalyst concentration of $25 \mathrm{ppm}$ and reaction temperature of $140^{\circ} \mathrm{C}$ were used as other conditions. A high circulation flow rate of $7,500 \mathrm{~kg} / \mathrm{h}$ was adopted to minimize temperature and concentration differences (maximum $\Delta T=$ $1^{\circ} \mathrm{C}$ ). With a residence time of $3 \mathrm{~h}$ in each reactor, the authors obtained a residual EO concentration in the loop of $0.3 \%$ and a product with a polydispersity index of 1.11 .

In 2016, Aigner et al. filed a patent claiming a new reactor technology dedicated to the continuous alkoxylation reaction of a generic substrate with active hydrogen atoms (Aigner et al., 2016). The reactor is designed as a concentric tubular reactor in which an annular space is obtained for performing the reaction continuously (see sketch in Figure 9). In this way, the annular gap reaction volume (width $6.5 \mathrm{~mm}$, diameter 5 inches, length $5 \mathrm{~m}$ ) is very similar to a thin film with enhanced properties of thermal exchange and able to achieve safe operation. Such a reactor system is characterized by a $L / D$ ratio of about 770 and is able to achieve a product throughput of $250 \mathrm{~kg} / \mathrm{h}$ (7 mol EO/mol n-nonyl phenol) in correspondence to 
a residence time of roughly $160 \mathrm{~s}$ and with a productivity of $22,000 \mathrm{~kg} /\left(\mathrm{h} \cdot \mathrm{m}^{3}\right)$. The authors claim the possibility to complete the reaction either in a separate tank or in the same reactor by introducing a higher volume at its bottom. In this way, products of different properties can be produced. Despite the fact that this reactor was built in a quite complex way, it opens the perspective of a real industrial utilization in the field of alkoxylation technology.

In the patent of Lai et al. (2019), two CSTR reactors connected in series allowed to obtain a polyolether constituted by EO/PO copolymer (Hreczuch et al., 2016) using DMC as catalyst $(20 \mathrm{ppm})$ at a temperature of $140^{\circ} \mathrm{C}$. Glycerol was used as starter and in the final product a weight ratio $\mathrm{PO} / \mathrm{EO}$ of 12 was obtained.

Another very interesting reactor configuration was proposed by Nikbin et al. (2018). The continuous reactor was assembled as three concentric tubes (tube-in-tube setup) schematically represented in Figure 10. In the inner, small-diameter tube, alkoxide is fed and can be distributed along the reactor axis at different axial positions; in the intermediate annular section, the reaction zone, the starter is fed and the reaction occurs with alkoxide coming from holes in the inner tube. Between the larger external tube and the intermediate one, the cooling fluid is fed allowing an optimal temperature control.

With this configuration, the authors described the use of a very long reactor $(200 \mathrm{~m})$ with a volume of $50 \mathrm{~m}^{3}$. The reactor was operated in three sections to demonstrate the flexibility of the operation: in the first $50 \mathrm{~m}$, PO was fed through the holes of internal tube; in the next $104 \mathrm{~m}$, EO was added in the same way and the remaining $46 \mathrm{~m}$ were used as cooking section.

\section{REFERENCES}

Aigner, R., Hirsch, D., and Lagnaz, A. (2016). Process and Apparatus for Continuous High Temperature Short-Time Alkoxylation (Ethoxylation, Propoxylation) of Chemical Substances With Active Hydrogen Atoms. US9242217B2.

Dessimoz, A. L. (2011). Intensification of gas/liquid chemical synthesis using microreactors and new operating windows (École Polytechnique Fédérale De Lausanne, Thèse N. 5142). EPFL, Lausanne, Switzerland.

Di Serio, M., Tesser, R., Russo, V., Turco, R., Vitiello, R., Sun, Y., et al. (2015). Catalysts for the ethoxylation of esters. J. Surfactants Deterg. 18, 913-918. doi: 10.1007/s11743-015-1719-1

Di Serio, M., Tesser, R., and Santacesaria, E. (2005). Comparison of different reactor types used in the manufacture of ethoxylated, propoxylated products. Ind. Eng. Chem. Res. 44, 9482-9489. doi: 10.1021/ie0502234

Gustin, J. (2000). "Safety of ethoxylation reactions," in IChemE Symposium Series No. 147 (Manchester), 19.

Herfeld, W., Hessel, V., and Löwe, G. (2000). Microreactors: New Technology for Modern Chemistry. New York, NY: Wiley-VCH. doi: 10.1002/3527601953

Hinz, W., and Dexheimer, E. M. (2002). Continuous Process for the Production of Sucrose-Based Polyether Polyols. US6380367B1.

Hreczuch, W., Chruściel, A., Dabrowska, K., Di Serio, M., and Yongqiang, S. (2016). Characteristics of block copolymers of methyl oxirane and oxirane derivatives of 2-ethylhexanol as obtained with $\mathrm{KOH}$ and dimetalcyanide type catalyst. Tenside Surfactants Deterg. 53, 259-264. doi: 10.3139/113.110431

Hubel, R., Markowz, G., Recksik, M., Rudek, M., Wewers, D., and Zeller-Schuldes, F. (2010). Alkoxylation in Microstructured Capillary Reactors. US7858829B2.

\section{CONCLUSION}

If we consider the recent findings reviewed in this paper, a promising perspective is nowadays available for performing alkoxylation reactions in continuous modality. It has been demonstrated that specifically designed continuous reactors can furnish very good performances in terms of productivity and for ensuring safe operation in the adopted conditions. The reactors are characterized by sufficient flexibility to achieve different alkoxylation degrees being, in this way, suitable for different productions. The obtained productivity is sufficiently high to guarantee, also considering reactor modularity, the possibility of useful industrial applications. Employing these emerging technologies, a new era in alkoxylation technology could start in the near future.

In perspective, more experimental and theoretical activities are needed to confirm the interesting data that emerged from the preliminary results reported in this review to achieve the conceptualization of new open process windows for the alkoxylation reaction, realizing prototypes solving the numbering-up issues (Herfeld et al., 2000). Moreover, it must be pointed out that these achievements in the improvement of microreactor technology will give a sure help in solving the new emerging COVID-19 challenges, which require safer and more localized specialized production.

\section{AUTHOR CONTRIBUTIONS}

MD drew the initial idea of the work and directed the workgroup composed by the other authors, who gave the same contribution as each of them edited part of the review. All authors contributed to the article and approved the submitted version.

Kralisch, D., Streckmann, I., Ott, D., Krtschil, U., Santacesaria, E., Di Serio, M., et al. (2012). Transfer of the epoxidation of soybean oil from batch to flow chemistry guided by cost and environmental issues. ChemSusChem 5, 300-311. doi: $10.1002 /$ cssc. 201100445

Krtschil, U., Hofmann, C., Lob, P., Schutt, C., Schorcht, P., and Streuber, M. (2013). Novel manufacturing techniques for microstructured reactors in industrial dimensions. Green Process. Synth. 2, 451-463. doi: 10.1515/gps-2013-0066

Lai, J., Wray, W. D., Lenahan, R. A., Reese, J. R., and Morrison, D. M. (2019). Systems and Processes for Producing Polyether Polyols. US10258953B2.

McDaniel, K. G., and Reese, J. R. (2007a). Continuous Process for the Production of Ethoxylates. EP2223953A1.

McDaniel, K. G., and Reese, J. R. (2007b). High Productivity Alkoxylation Processes. EP2325230A1.

McDaniel, K. G., and Reese, J. R. (2008a). Continuous Processes for the Production of Alkylphenol Ethoxylates. US0132728A1.

McDaniel, K. G., and Reese, J. R. (2008b). High Productivity Alkoxylation Processes. US0167501A1.

Nikbin, N. N., Villa, C. M., Remacha, M. J. N., Khan, I., Heat, W. H., Pendergast, J. G., et al. (2018). Alkoxylation Process Using Tubular Reactor. WO2018/057438A1.

Rupp, M., Ruback, W., and Klemm, E. (2013a). Alcohol ethoxylation kinetics: proton transfer influence on product distribution in microchannels. Chem. Eng. Process. Process Intensif. 74, 187-192. doi: 10.1016/j.cep.2013.09.006

Rupp, M., Ruback, W., and Klemm, E. (2013b). Octanolethoxylation in microchannels. Chem. Eng. Process. Process Intensif. 74, 19-26. doi: 10.1016/j.cep.2013.09.012 
Russo, V., Protasova, L., Turco, R., de Croon, M. H. J. M., Hessel, V., and Santacesaria, E. (2013). Hydrogen peroxide decomposition on manganese oxide supported catalyst: from batch reactor to continuous microreactor. Ind. Eng. Chem. Res. 52, 7668-7676. doi: 10.1021/ie303543x

Salzano, E., Di Serio, M., and Santacesaria, E. (2007a). The evaluation of risks of ethoxylation reactors. Process Saf. Prog. 26, 304-311. doi: 10.1002/prs. 10212

Salzano, E., Di Serio, M., and Santacesaria, E. (2007b). The role of recirculation loop on the risk of ethoxylation processes. J. Loss Prev. Process Ind. 20, 238-250. doi: 10.1016/j.jlp.2007.03.016

Santacesaria, E., Tesser, R., and Di Serio, M. (2018). Polyethoxylation and polypropoxylation reactions: kinetics, mass transfer and industrial reactor design. Chin. J. Chem. Eng. 26, 1235-1251. doi: 10.1016/j.cjche.2018.02.020

Umbach, W., and Stein, W. (1971). Continuous alkoxylation process. JAOCS 48, 394-397. doi: 10.1007/BF02637359

Verwijs, J. W., Weston, J. W., Papadopulos, W. J. S., Elwell, R. J., and Villa, C. M. (2008). Continuous Process and System of Producing Polyether Polyols. US7378559B2.

Villa, C. M., Weston, J. W., Jain, P., Thompson, L. H., and Masy, J.-P. (2014). Continuous Loop Flow Process for Polyether Polyol Production. US8912364B2.
Weston, J. W., Villa, C. M., Masy, J.-P., and Seavey, K. C. (2012). Method for Continuously Producing Low Equivalent Weigth Polyols Using Double Metal Cyanide Catalysts. US0283483A1.

Yamada, K., Kasahara, N., Toyota, Y., Suzuki, C., Ikai, S., and Hatano, H. (2006). Method for Continuously Producing a Polyether. US7012164B2.

Conflict of Interest: ES was employed by the company Eurochem Engineering. WH was employed by the company MEXEO.

The remaining authors declare that the research was conducted in the absence of any commercial or financial relationships that could be construed as a potential conflict of interest.

Copyright (c) 2020 Tesser, Russo, Santacesaria, Hreczuch and Di Serio. This is an open-access article distributed under the terms of the Creative Commons Attribution License (CC BY). The use, distribution or reproduction in other forums is permitted, provided the original author(s) and the copyright owner(s) are credited and that the original publication in this journal is cited, in accordance with accepted academic practice. No use, distribution or reproduction is permitted which does not comply with these terms. 